\title{
Association between diabetes mellitus and active periodontitis in Korean adults from Korea National Health and Nutrition Examination Surveys 2010-2015
}

\author{
Jae-Hong Lee ${ }^{1,2 \dagger}$, Do-Hyung Kim ${ }^{1,2 \dagger}$, Bo-Ram Nam ${ }^{1,2}$, Seong-Nyum Jeong ${ }^{1,2 *}$ \\ ${ }^{1}$ Department of Periodontology, Wonkwang University Daejeon Dental Hospital, Wonkwang University College of Dentistry, Daejeon, Korea \\ ${ }^{2}$ Institute of Wonkwang Dental Research, Wonkwang University College of Dentistry, Iksan, Korea
}

\begin{abstract}
Periodontitis and diabetes mellitus (DM) are chronic diseases that require continuous management and are well known for their mutual relationship. The present study used the most recent Korea National Health and Nutrition Examination Surveys (KNHANES $\mathrm{V}$ and VI) to determine the relationship between active periodontitis and DM in a Korean population. Multivariate logistic regression analysis was performed with confounding variables to estimate odds ratios with $95 \%$ confidence intervals. We enrolled a total of 14,662 participants, and among them, 4,819 participants were diagnosed with active periodontitis and 2,095 were diagnosed with DM. The risk for active periodontitis was 1.20 times higher in the presence of DM adjusted for demographic, socioeconomic and health-related factors, and comorbid disease and was statistically significant $(p<0.001)$. This research has provided evidence of a relationship between active periodontitis and DM in a Korean population.
\end{abstract}

Key Words: Diabetes mellitus, Periodontal disease, Risk factors

(c) This is an open-access article distributed under the terms of the Creative Commons Attribution Non-Commercial License (http://creativecommons.org/licenses/by-nc/4.0) which permits unrestricted noncommercial use, distribution, and reproduction in any medium, provided the original work is properly cited.

\section{INTRODUCTION}

Diabetes mellitus (DM) is common chronic metabolic disease characterized by hyperglycemia due to insulin secretion or resistance and, can cause complication in many organs such as eyes and kidney [1]. Recently, prevalence of DM is rising as 366 million people are presumed to have DM globally in 2013 and this number is predicted to rise up to 590 million by 2035 [2]. Most common form of DM is type $2 \mathrm{DM}$ (T2DM) which accounts for $90 \%-95 \%$ and caused by insulin resistance. Second most common form of DM is type $1 \mathrm{DM}$ (T1DM) which accounts for $5 \%-10 \%$ of all DM and caused by $\beta$-cell destruction in pancreas [3]. Due to this difference in pathogenic mechanism, T1DM and T2DM show different age of onset.

Periodontitis is chronic inflammatory disease, related to gingiva and destruction of alveolar bone with up to $90 \%$ of prevalence globally [4]. According to 1999 American association of periodontology classification, there are 2 types of periodontitis which are chronic periodontitis and aggres-

Received June 23, 2019; Accepted August 26, 2019

Corresponding author: Seong-Nyum Jeong, Department of Periodontology, Wonkwang University Daejeon Dental Hospital, Wonkwang University College of Dentistry, 77 Dunsan-ro, Seo-gu, Daejeon 35233, Korea.

Tel: +82-42-366-1114, Fax: +82-42-366-1115, E-mail: seongnyum@wonkwang.ac.kr

${ }^{\dagger}$ These two authors contributed equally to this study.

Copyright $\odot$ 2019, Oral Biology Research Institute 
sive periodontitis. Chronic periodontitis progress slowly with plaque and calculus. In contrast, aggressive periodontitis shows rapid destruction of alveolar bone in relatively young patients [5].

Periodontitis has long been regarded as the sixth complication of $\mathrm{DM}$, and diabetes is considered as a major risk factor for chronic periodontitis [6-8]. DM itself does not cause periodontitis, but promotes and accelerates periodontal damage, and blood glucose levels are considered to be important determinants in this relationship [9,10]. Recent studies have shown that there is a bi-directional relationship between the two conditions, which has a negative effect on each other [11].

Periodontitis and DM are chronic diseases which need continuous management. Current study investigates relationship between active periodontitis and DM in Korean population, based on most recent Korea National Health and Nutrition Examination Surveys (KNHANES V and VI), which were collected by the Korea Center for Disease Control and Prevention (KCDC) and released in 2017.

\section{MATERIALS AND METHODS}

\section{Study design and data collection}

This study is based on nationally representative population-based survey data acquired from KNHANES $V$ and VI, which was implemented periodically at the Ministry of Health and Welfare and KCDC from 2000 to 2015 [12]. It included four different components: a health interview, a health behavior interview, a nutrition survey, and a health and oral examination. Investigators conducted face-to-face interview with each participant and all collected data were anonymized to protect the identity of individuals before analysis.

\section{Ethics statement}

This study was approved by the Institutional Review Board (IRB) of the KCDC (IRB no. 2010-02CON-21-C, 2011-02CON-06-C, 2012-01EXP-01-2C, 2013-07CON03-4C, and 2013-12EXP-03-5C). KNHANES VI (2015) was conducted without consideration by the IRB in accordance with government legislation for public welfare under the Bioethics Act (Act no. 2-1). All enrolled participants provided written informed consent in accordance with the IRB guidelines. In addition, this study was written according to the Strengthening the Reporting of Observational Studies in Epidemiology (STROBE) guideline for reporting retrospective and cohort studies (www.strobe-statement.org).

\section{Outcome variables}

DM in adults aged $\geq 20$ years was defined as follows: (1) fasting plasma glucose level of $\geq 126 \mathrm{mg} / \mathrm{dL}$ or self-reported diagnosed DM by a medical doctor, or (3) self-reported receiving DM treatment with the current use of insulin and/or hypoglycemic agents. Based on these three different measures for DM, all participants were classified as diabetic and non-diabetic condition.

The World Health Organization community periodontal index (CPI) was used to classify participants as periodontally compromised or periodontally healthy condition. Periodontitis was defined as a CPI value of $>3$, indicating that $\geq 1$ site had a probing pocket $\geq 3.5 \mathrm{~mm}$ in the index teeth (including upper right and lower left central incisors, and eight molars). All participants in the oral examination and interview were assessed using the CPI periodontal probe and mouth mirror. Active periodontitis was assessed on the basis of CPI and limited to participants where the general public health dentists determined that periodontal treatment was indispensable.

\section{Covariate variables}

The following potential confounding sociodemographic factors, life-style related factors, and comorbid disease were collected and assessed from the KNHANES 2010-2015 database: (1) age (three groups: those aged 20-39 years [young], 40-59 years [middle-aged] and $\geq 60$ [old age], (2) sex (two groups), (3) household income (four quartiles), (4) residence area (two groups: urban $[\geq 40,000$ residents] and rural $[<40,000$ residents] $),(5)$ marital status, (6) education level (four groups: $\leq$ elementary school, middle school, high school, and $\geq$ college), (7) smoking status (two groups: non-smoker including former smoker 
and current smoker), (8) alcohol intake (four groups: none, 1-4 times/month, 2-3 times/week, and $\geq 4$ times/week), (9) body mass index (BMI; three groups: underweight $[<18.5$ $\left.\mathrm{kg} / \mathrm{m}^{2}\right]$, normal $\left[18.5-25 \mathrm{~kg} / \mathrm{m}^{2}\right]$, and obese [ $\left.\geq 25 \mathrm{~kg} / \mathrm{m}^{2}\right]$ ), and (10) comorbid disease (including hyperlipidemia, stroke, angina pectoris [AP] and myocardial infarction [MI], and rheumatoid arthritis, which were self-reported diagnosed DM by a medical doctor).

\section{Statistical analysis}

Descriptive statistics were reported for demographic, socioeconomic (household income, residence area, marital status, and education level) and health-related (smoking status, alcohol intake, and BMI) factors, and comorbid disease (hyperlipidemia, stroke, AP and MI, and rheumatoid arthritis) as mean \pm standard deviation or by frequency percentages (\%). KNHANES was conducted with complex sampling analysis by weighting individual factors for minimized bias. To determine the association between DM and active periodontitis, especially, by age differences, multivariate logistic regression analysis was performed with confounding variables. From model 1 to model 3, de- mographic, socioeconomic and health-related factors, and comorbid disease were sequentially entered in the model. The odds ratio (OR) and 95\% confidence interval were calculated, and $p$-values $<0.05$ were considered statistically significant. Statistical analyses were performed using the Statistical Analysis System (SAS) Enterprise Miner ver. 9.4 (SAS Institute, Cary, NC, USA).

\section{RESULTS}

\section{Baseline characteristics}

According to the STROBE recommendations for observational studies, the baseline characteristics of the study participants are presented in Fig. 1 and Table 1. Among the 73,353 Korean adults who were originally included, 14,662 (20.0\%) participants were finally recruited, comprising 8,432 males (57.5\%) and 6,230 females (42.5\%). As a result of examining the periodontal status of the participants, 4,819 (32.9\%) were diagnosed with active periodontitis and 2,095 (14.3\%) of the study participants had DM. Those aged $40-59$ years $(n=5,620)$ accounted for $38.3 \%$ of the surveyed participants, while 3,745 (25.5\%) were had household in-

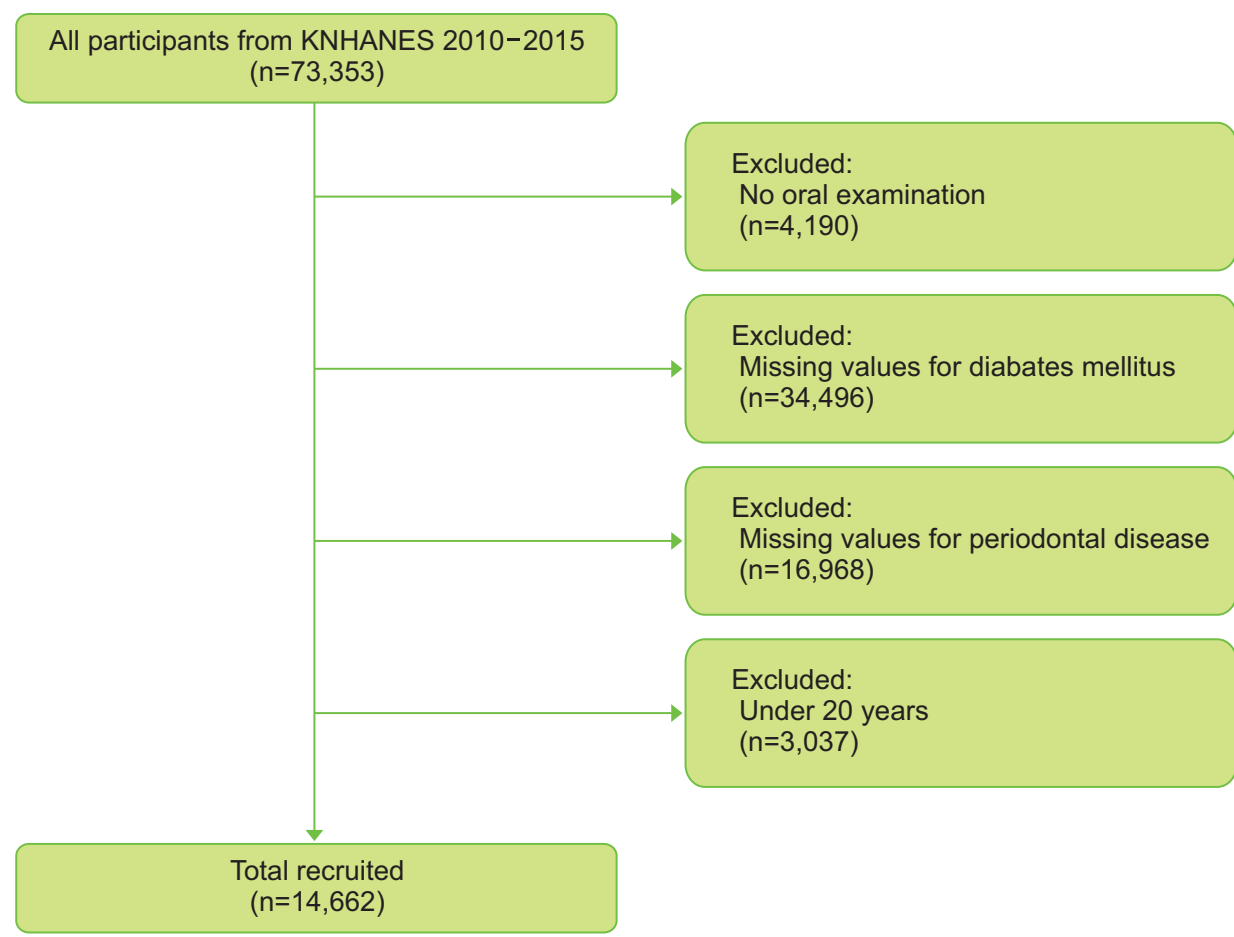

Fig. 1. Flow chart of the inclusion and exclusion of participants. KNHANES, Korea National Health and Nutrition Examination Surveys. 
Table 1. General characteristics of the participants in the KNHANES $\mathrm{V}$ and VI performed from 2010 to $2015(\mathrm{n}=14,662)$

\begin{tabular}{|c|c|c|}
\hline Characteristic & Division & n (\%) \\
\hline Active periodontitis & & $4,819(32.9)$ \\
\hline $\mathrm{DM}$ & & $2,095(14.3)$ \\
\hline \multirow[t]{7}{*}{ Demographic variables } & Sex & \\
\hline & Male & $8,432(57.5)$ \\
\hline & Female & $6,230(42.5)$ \\
\hline & Age (y) & \\
\hline & 20-39 & $3,945(26.9)$ \\
\hline & $40-59$ & $5,620(38.3)$ \\
\hline & $\geq 60$ & $5,097(34.8)$ \\
\hline \multirow[t]{16}{*}{ Socioeconomic variables } & Household income & \\
\hline & First quartile (low) & $3,504(23.9)$ \\
\hline & Second quartile & $3,745(25.5)$ \\
\hline & Third quartile & $3,718(25.4)$ \\
\hline & Fourth quartile (high) & $3,695(25.2)$ \\
\hline & Residence area ${ }^{\star}$ & \\
\hline & Urban & $11,865(80.9)$ \\
\hline & Rural & $2,797(19.1)$ \\
\hline & Marital status & \\
\hline & Married & $12,609(86.0)$ \\
\hline & Not married & $2,053(14.0)$ \\
\hline & Education level & \\
\hline & $\leq$ Elementary school & $3,504(23.9)$ \\
\hline & Middle school & $1,616(11.0)$ \\
\hline & High school & $4,916(33.5)$ \\
\hline & $\geq$ College & $4,626(31.6)$ \\
\hline \multirow[t]{12}{*}{ Health-related variables } & Smoking status & \\
\hline & Non-smoker ${ }^{\dagger}$ & $11,978(81.7)$ \\
\hline & Current smoker & $2,684(18.3)$ \\
\hline & Alcohol intake & \\
\hline & None & $4,445(30.3)$ \\
\hline & 1-4 times/month & $7,169(48.9)$ \\
\hline & 2-3 times/week & $2,095(14.3)$ \\
\hline & $\geq 4$ times/week & $953(6.5)$ \\
\hline & Body mass index $\left(\mathrm{kg} / \mathrm{m}^{2}\right)$ & \\
\hline & $<18.5$ (underweight) & $579(3.9)$ \\
\hline & $18.5-25$ (normal) & $9,173(62.6)$ \\
\hline & $\geq 25$ (obese) & $4,910(33.5)$ \\
\hline \multirow[t]{4}{*}{ Comorbid disease } & Hyperlipidemia & $2,368(16.2)$ \\
\hline & Stroke & $406(2.8)$ \\
\hline & $\mathrm{AP}$ and $\mathrm{MI}$ & $464(3.2)$ \\
\hline & Rheumatoid arthritis & $286(2.0)$ \\
\hline
\end{tabular}

KNHANES, Korea National Health and Nutrition Examination Surveys; DM, diabetes mellitus; AP, angina pectoris; MI, myocardial infarction.

${ }^{\star}$ Classified using a cutoff of 40,000 residents, ${ }^{\dagger}$ including former smokers.

comes in the second quartile, 11,865 (80.9\%) lived in urban areas, 12,609 (86.0\%) were married, 4,916 (33.5\%) attended high school, 11,978 (81.7\%) were non-smokers, 7,169
(48.9\%) consumed alcohol once or fourth a month, and 9,173 (62.6\%) had normal BMI. Among the participants, 2,368 (16.2\%) had hyperlipidemia, 406 (2.8\%) had experienced a stroke, 464 (3.2\%) had AP or experienced MI, and $286(2.0 \%)$ had rheumatoid arthritis.

\section{Prevalence of active periodontitis with diabetes mellitus and without diabetes mellitus}

Among active periodontitis patients with DM, 290 (28.8\%) had household incomes in the second quartile, $752(74.8 \%)$ lived in urban areas, 986 (98.0\%) were married, 489 (48.6\%) were under elementary school educated, $792(78.7 \%)$ were non-smokers, 457 (45.4\%) were non-alcohol consumers, $531(52.8 \%)$ had normal BMI, 382 (38.0\%) had hyperlipidemia, 91 (9.0\%) had experienced a stroke, 97 (9.6\%) had AP or experienced MI, and $30(3.0 \%)$ had rheumatoid arthritis (Table 2).

\section{Factors associated with active periodontitis patients with and without diabetes mellitus}

The risk for active periodontitis with DM was analyzed by logistic regression analysis (Table 3 ). In model 1 , the effect of DM on active periodontitis was analyzed using multivariate analysis after adjusting for sex and age, the risk for active perioidontitis was 1.28 times higher in the presence of DM, which was statistically significant $(p<0.001)$. In model 2 , which was adjusted for demographic, socioeconomic and health-related factors, the risk for active periodontitis was 1.18 times higher in the presence of DM, which was statistically significant $(p<0.001)$. In model 3 , which was adjusted for demographic, socioeconomic and health-related factors, and comorbid disease, the risk for active periodontitis was 1.20 times higher in the presence of DM, which was also statistically significant $(p<0.001)$.

\section{DISCUSSION}

Chronic periodontitis and DM have close relationship, especially in DM patient with uncontrolled hyperglycemia [13]. In uncontrolled DM patient, periodontitis is more severe in its prevalence and severity [14]. Likewise, peri- 
Table 2. Distribution of active periodontitis patients with and without DM

\begin{tabular}{|c|c|c|c|c|}
\hline \multirow{2}{*}{ Characteristic } & \multicolumn{2}{|c|}{ Active perioidontitis } & \multicolumn{2}{|c|}{ Non-active periodontitis and healthy } \\
\hline & With DM (n, \%) & Without DM (n, \%) & With DM (n, \%) & Without DM (n, \%) \\
\hline Total population & 1,006 & 3,813 & 1,089 & 8,754 \\
\hline \multicolumn{5}{|l|}{ Sex 1} \\
\hline Male & $473(47.0)$ & $1,859(48.8)$ & $601(55.2)$ & $5,499(62.8)$ \\
\hline Female & $533(53.0)$ & $1,954(51.2)$ & $488(44.8)$ & $3,255(37.2)$ \\
\hline \multicolumn{5}{|l|}{ Age (y) } \\
\hline $20-39$ & $11(1.1)$ & $407(10.7)$ & $45(4.1)$ & $3,482(39.8)$ \\
\hline $40-59$ & $270(26.8)$ & $1,767(46.3)$ & $276(25.3)$ & $3,307(37.8)$ \\
\hline$\geq 60$ & $725(72.1)$ & $1,639(43.0)$ & $768(70.5)$ & $1,965(22.4)$ \\
\hline \multicolumn{5}{|l|}{ Household income } \\
\hline First quartile (low) & $284(28.2)$ & $973(25.5)$ & $300(27.5)$ & $1,947(22.2)$ \\
\hline Second quartile & $290(28.8)$ & $1,017(26.7)$ & $259(23.8)$ & $2,179(24.9)$ \\
\hline Third quartile & $205(20.4)$ & $942(24.7)$ & $256(23.5)$ & $2,315(26.4)$ \\
\hline Fourth quartile (high) & $227(22.6)$ & $881(23.1)$ & $274(25.2)$ & $2,313(26.4)$ \\
\hline \multicolumn{5}{|l|}{ Residence area $^{*}$} \\
\hline Urban & $752(74.8)$ & $2,860(75.0)$ & $879(80.7)$ & $7,374(84.2)$ \\
\hline Rural & $254(25.2)$ & $953(25.0)$ & $210(19.3)$ & $1,380(15.8)$ \\
\hline \multicolumn{5}{|l|}{ Marital status } \\
\hline Married & $986(98.0)$ & $3,630(95.2)$ & $1,053(96.7)$ & $6,940(79.3)$ \\
\hline Not married & $20(2.0)$ & $183(4.8)$ & $36(3.3)$ & $1,814(20.7)$ \\
\hline \multicolumn{5}{|l|}{ Education level } \\
\hline$\leq$ Elementary school & $489(48.6)$ & $1,159(30.4)$ & $479(44.0)$ & $1,377(15.7)$ \\
\hline Middle school & $159(15.8)$ & $547(14.3)$ & $175(16.1)$ & $735(8.4)$ \\
\hline High school & $237(23.6)$ & $1,233(32.3)$ & $269(24.7)$ & $3,177(36.3)$ \\
\hline$\geq$ College & $121(12.0)$ & $874(22.9)$ & $166(15.2)$ & $3,465(39.6)$ \\
\hline \multicolumn{5}{|l|}{ Smoking status } \\
\hline Non-smoker ${ }^{\dagger}$ & $792(78.7)$ & $2,877(75.5)$ & $933(85.7)$ & $7,376(84.3)$ \\
\hline Current smoker & $214(21.3)$ & $936(24.5)$ & $156(14.3)$ & $1,378(15.7)$ \\
\hline \multicolumn{5}{|l|}{ Alcohol intake } \\
\hline None & $457(45.4)$ & $1,182(31.0)$ & $486(44.6)$ & $2,320(26.5)$ \\
\hline 1-4 times/month & $344(34.2)$ & $1,649(43.2)$ & 409 (37.6) & $4,767(54.5)$ \\
\hline 2-3 times/week & $124(12.3)$ & $626(16.4)$ & $116(10.7)$ & $1,229(14.0)$ \\
\hline$\geq 4$ times/week & $81(8.1)$ & $356(9.3)$ & $78(7.2)$ & $438(5.0)$ \\
\hline \multicolumn{5}{|l|}{ Body mass index $\left(\mathrm{kg} / \mathrm{m}^{2}\right)$} \\
\hline$<18.5$ (underweight) & $18(1.8)$ & $95(2.5)$ & $14(1.3)$ & $452(5.2)$ \\
\hline $18.5-25$ (normal) & $531(52.8)$ & $2,240(58.7)$ & $601(55.2)$ & $5,801(66.3)$ \\
\hline$\geq 25$ (obese) & $457(45.4)$ & $1,478(38.8)$ & $474(43.5)$ & $2,501(28.6)$ \\
\hline \multicolumn{5}{|l|}{ Comorbid disease } \\
\hline Hyperlipidemia & $382(38.0)$ & $573(15.0)$ & $441(40.5)$ & $972(11.1)$ \\
\hline Stroke & $91(9.0)$ & $103(2.7)$ & $81(7.4)$ & $131(1.5)$ \\
\hline $\mathrm{AP}$ and $\mathrm{MI}$ & $97(9.6)$ & $127(3.3)$ & $98(9.0)$ & $142(1.6)$ \\
\hline Rheumatoid arthritis & $30(3.0)$ & $63(1.7)$ & $37(3.4)$ & $156(1.8)$ \\
\hline
\end{tabular}

DM, diabetes mellitus; AP, angina pectoris; MI, myocardial infarction.

${ }^{*}$ Classified using a cutoff of 40,000 residents, ${ }^{\dagger}$ including former smokers.

odontitis also affects DM as periodontitis itself can worsen glycemic control of DM patient [15]. Mechanism of this interrelations between periodontitis and DM is still not fully understood, but the receptor activator of nuclear factor- $\kappa \mathrm{B}$ (RANK)/RANK ligand/osteoprotegerin axis, receptor for advanced glycation end products pathway and oxidative stress mechanism are reported to be related in recent research [16].

DM is a very frequent metabolic disorder characterized by the presence of chronic hyperglycemia because of low 
Table 3. Multivariate logistic regression analysis of risk for active periodontitis with DM

\begin{tabular}{|c|c|c|c|c|c|c|}
\hline \multirow{2}{*}{ DM (ref: no) } & \multicolumn{2}{|c|}{ Model 1} & \multicolumn{2}{|l|}{ Model 2} & \multicolumn{2}{|c|}{ Model 3} \\
\hline & OR (95\% CI) & $p$-value & OR (95\% CI) & $p$-value & OR (95\% CI) & $p$-value \\
\hline \multicolumn{7}{|l|}{ Active periodontitis } \\
\hline Yes & $1.28(1.15-1.41)$ & $<0.001$ & $1.18(1.06-1.31)$ & $<0.001$ & $1.20(1.08-1.33)$ & $<0.001$ \\
\hline \multicolumn{7}{|l|}{ Sex } \\
\hline Female & $0.75(0.68-0.83)$ & $<0.001$ & $0.62(0.55-0.70)$ & $<0.001$ & $0.56(0.49-0.63)$ & $<0.001$ \\
\hline \multicolumn{7}{|l|}{ Age } \\
\hline $40-59$ & $6.99(5.28-9.25)$ & $<0.001$ & $5.81(4.25-7.95)$ & $<0.001$ & $4.81(3.51-6.57)$ & $<0.001$ \\
\hline$\geq 60$ & $26.38(20.07-34.66)$ & $<0.001$ & $17.79(12.88-24.58)$ & $<0.001$ & $12.33(8.91-17.06)$ & $<0.001$ \\
\hline \multicolumn{7}{|l|}{ Household income } \\
\hline Second quartile & & & $0.87(0.76-1.00)$ & 0.060 & $0.90(0.78-1.04)$ & 0.161 \\
\hline Third quartile & & & $0.74(0.64-0.85)$ & $<0.001$ & $0.72(0.62-0.85)$ & $<0.001$ \\
\hline Fourth quartile & & & $0.89(0.77-1.03)$ & 0.141 & $0.87(0.74-1.01)$ & 0.068 \\
\hline \multicolumn{7}{|l|}{ Residence area } \\
\hline Urban & & & $0.98(0.70-1.38)$ & $<0.001$ & $1.12(0.99-1.27)$ & 0.064 \\
\hline \multicolumn{7}{|l|}{ Marital status } \\
\hline Married & & & $1.03(0.75-1.42)$ & 0.845 & $1.10(0.79-1.52)$ & 0.549 \\
\hline \multicolumn{7}{|l|}{ Education level } \\
\hline Middle school & & & $0.94(0.81-1.10)$ & 0.462 & $0.88(0.75-1.03)$ & 0.119 \\
\hline High school & & & $0.71(0.62-0.82)$ & $<0.001$ & $0.70(0.60-0.81)$ & $<0.001$ \\
\hline$\geq$ College & & & $0.56(0.47-0.67)$ & $<0.001$ & $0.56(0.47-1.52)$ & $<0.001$ \\
\hline \multicolumn{7}{|l|}{ Smoking status } \\
\hline Current smoker & & & $1.24(1.07-1.44)$ & 0.003 & $1.25(1.08-1.45)$ & 0.002 \\
\hline \multicolumn{7}{|l|}{ Alcohol intake } \\
\hline 1-4 times/month & & & $1.03(0.82-1.30)$ & 0.758 & $1.00(0.79-1.27)$ & 0.960 \\
\hline 2-3 times/week & & & $1.14(0.93-1.40)$ & 0.181 & $1.10(0.89-1.35)$ & 0.362 \\
\hline$\geq 4$ times/week & & & $1.61(1.31-1.99)$ & $<0.001$ & $1.55(1.26-1.92)$ & $<0.001$ \\
\hline \multicolumn{7}{|l|}{ Body mass index $\left(\mathrm{kg} / \mathrm{m}^{2}\right)$} \\
\hline$<18.5$ (underweight) & & & $0.52(0.35-0.76)$ & $<0.001$ & $0.58(0.39-0.86)$ & 0.007 \\
\hline$\geq 25$ (obese) & & & $1.49(1.35-1.65)$ & $<0.001$ & $1.39(1.25-1.54)$ & $<0.001$ \\
\hline \multicolumn{7}{|l|}{ Comorbid disease } \\
\hline Hyperlipidemia & & & & & $2.73(2.44-3.06)$ & $<0.001$ \\
\hline Stroke & & & & & $1.78(1.43-2.21)$ & $<0.001$ \\
\hline $\mathrm{AP}$ and $\mathrm{MI}$ & & & & & $1.71(1.39-2.10)$ & $<0.001$ \\
\hline Rheumatoid arthritis & & & & & $1.15(0.85-1.56)$ & 0.361 \\
\hline
\end{tabular}

Model 1: adjusted for demographic variables. Model 2: adjusted for demographic, socioeconomic (household income, residence area, marital status, and education level) and health-related (smoking status, alcohol intake, and body mass index) variables. Model 3: adjusted for demographic, socioeconomic (household income, residence area, marital status, and education level) and health-related (smoking status, alcohol intake, and body mass index) variables, and comorbid disease (hyperlipidemia, stroke, AP and MI, and rheumatoid arthritis).

$\mathrm{DM}$, diabetes mellitus; OR, odds ratio; CI, confidence interval; AP, angina pectoris; MI, myocardial infarction.

levels of both insulin secretion and its action [14]. T1DM is a type of juvenile diabetes that accounts for more than $85 \%$ of all diabetes patients under 20 years of age, accounting for $5 \%-10 \%$ of the world's DM population. T2DM accounts for $90 \%$ of diabetes cases worldwide [17]. If patient shows HbA1C level above 6.5\%, fasting plasma glucose level above $125 \mathrm{mg} / \mathrm{dL}(7.0 \mathrm{mmol} / \mathrm{L})$, 2-hour plasma glucose level above $200 \mathrm{mg} / \mathrm{dL}(11.1 \mathrm{mmol} / \mathrm{L})$, or random plasma glucose level above $200 \mathrm{mg} / \mathrm{dL}$ (11.1 mmol/L) with classic symptoms of hyperglycemia or hyperglycemic crisis, patient can be diagnosed as DM and DM can be classified as T1DM, T2DM, gestational diabetes, DM caused by other diseases, drugs or factors [1,3].

Cross-sectional and longitudinal studies have shown that the risk of periodontitis in DM patients is about 3-4 times higher than in non-DM patients [18]. Periodontitis was 
found in $57.9 \%$ of T1DM patients and $15.0 \%$ in non-DM patients [19]. In another study of periodontal status in children and adolescents with T1DM, prevalence of gingivitis and periodontitis was $20.8 \%$ and $5.9 \%$, respectively [20]. T2DM patients were more at risk for serious forms of periodontitis more than non-DM [21]. The OR of T1DM patients with attachment loss was 3.84 compared to non-DM patients [22]. In addition, more than $25 \%$ of T1DM patients with poor metabolic control showed areas with clinical attachment loss $>5 \mathrm{~mm}$, but only $10 \%$ of patients with good metabolic control showed [17]. T2DM patients were also significantly more likely to have clinical attachment loss of $>3 \mathrm{~mm}$ as well as $5 \mathrm{~mm}$ [17].

DM affects bone metabolism and decreases bone mineral density [17]. DM also significantly affects osteoblasts and reduces the number of osteogenic cells [17]. On the other hand, the production of osteoclasts increases. In patients with T1DM or T2DM, poor glycemic control results in increased bone resorption and increased bone loss [17]. DM patients had significantly higher gum bleeding depending on the level of glycemic control than well-controlled DM or non-DM patients [14]. In adults with T2DM, gingival inflammation was more frequent than in non-DM patients and the highest level of inflammation was seen in patients with poor glycemic control [23].

In a multivariate logistics regression analysis, patients with DM showed OR of 1.28, 1.18, and 1.20 respectively after adjusted with each model in this multivariate logistics analysis (Model 1, 2, and 3 described in Table 3). We found that odd ratio of active periodontitis was significantly higher in DM patients even after adjusting the other contributing factors of periodontitis.

We have used the most recent KNHANES database to find a relation between active periodontitis and DM after adjusting several factors. Active periodontitis and DM showed constant relation in all model of multivariate logistics regression analysis. DM also showed statistically significant relation between sex, age, house hold income, education level, alcohol intake, obesity and comorbid diseases in model 3. These results can be helpful for making health care policy for DM patients and active periodontitis patients since they are closely related.

\section{ACKNOWLEDGEMENTS}

This work was supported by the National Research Foundation of Korea (NRF) grant funded by the Korea government (MSIT) (No.2019R1A2C1083978).

\section{CONFLICTS OF INTEREST}

The authors declare that they have no competing interests.

\section{ORCID}

\author{
Jae-Hong Lee \\ https://orcid.org/0000-0002-2375-0141 \\ Do-Hyung Kim \\ https://orcid.org/0000-0001-7846-6175 \\ Bo-Ram Nam \\ https://orcid.org/0000-0001-5708-9956 \\ Seong-Nyum Jeong \\ https://orcid.org/0000-0003-4890-989X
}

\section{REFERENCES}

1. American Diabetes Association. Diagnosis and classification of diabetes mellitus. Diabetes Care 2013;36(Suppl 1):S67-S74. doi: 10.2337/dc13-S067.

2. Guariguata L, Whiting DR, Hambleton I, Beagley J, Linnenkamp U, Shaw JE. Global estimates of diabetes prevalence for 2013 and projections for 2035. Diabetes Res Clin Pract 2014;103:137-149. doi: 10.1016/j.diabres.2013.11.002.

3. American Diabetes Association. Classification and diagnosis of diabetes. Diabetes Care 2015; 38(Suppl 1):S8-S16. doi: $10.2337 / \mathrm{dc} 15-\mathrm{S} 005$.

4. Pihlstrom BL, Michalowicz BS, Johnson NW. Periodontal diseases. Lancet 2005;366:1809-1820. doi: 10.1016/ S0140-6736(05)67728-8.

5. American Academy of Periodontology Task Force Report on the Update to the 1999 Classification of Periodontal Diseases and Conditions. J Periodontol 2015;86:835-838. doi: 10.1902/jop.2015.157001.

6. Corlan Puşcu D, Ciuluvică RC, Anghel A, Mălăescu GD, Ciursaş AN, Popa GV, Agop Forna D, Busuioc CJ, Siloşi I. Periodontal disease in diabetic patients - clinical and histopathological aspects. Rom J Morphol Embryol 2016; 57:1323-1329.

7. Lee JH, Choi JK, Jeong SN, Choi SH. Charlson comorbidity 
index as a predictor of periodontal disease in elderly participants. J Periodontal Implant Sci 2018;48:92-102. doi: 10.5051/jpis.2018.48.2.92.

8. Lee JH, Lee JS, Park JY, Choi JK, Kim DW, Kim YT, Choi SH. Association of lifestyle-related comorbidities with periodontitis: a nationwide cohort study in Korea. Medicine (Baltimore) 2015;94:e1567. doi: 10.1097/ MD.0000000000001567.

9. Löe H. Periodontal disease. The sixth complication of diabetes mellitus. Diabetes Care 1993;16:329-334. doi: 10.2337/diacare.16.1.329.

10. Mealey BL, Moritz AJ. Hormonal influences: effects of diabetes mellitus and endogenous female sex steroid hormones on the periodontium. Periodontol 2000 2003;32:5981. doi: 10.1046/j.0906-6713.2002.03206.x.

11. Bascones-Martínez A, González-Febles J, Sanz-Esporrín J. Diabetes and periodontal disease. Review of the literature. Am J Dent 2014;27:63-67.

12. Kweon S, Kim Y, Jang MJ, Kim Y, Kim K, Choi S, Chun C, Khang YH, Oh K. Data resource profile: the Korea National Health and Nutrition Examination Survey (KNHANES). Int J Epidemiol 2014;43:69-77. doi: 10.1093/ije/dyt228.

13. Al-Khabbaz AK. Type 2 diabetes mellitus and periodontal disease severity. Oral Health Prev Dent 2014;12:77-82. doi: 10.3290/j.ohpd.a31223.

14. Mealey BL, Ocampo GL. Diabetes mellitus and periodontal disease. Periodontol 2000 2007;44:127-153. doi: 10.1111/ j.1600-0757.2006.00193.x.

15. Taylor GW, Burt BA, Becker MP, Genco RJ, Shlossman M, Knowler WC, Pettitt DJ. Severe periodontitis and risk for poor glycemic control in patients with non-insulindependent diabetes mellitus. J Periodontol 1996;67(10
Suppl):1085-1093. doi: 10.1902/jop.1996.67.10s.1085.

16. Badiger AB, Gowda TM, Chandra K, Mehta DS. Bilateral interrelationship of diabetes and periodontium. Curr Diabetes Rev 2019;15:357-362. doi: 10.2174/1573399815666 190115144534

17. Wu YY, Xiao E, Graves DT. Diabetes mellitus related bone metabolism and periodontal disease. Int J Oral Sci 2015;7:63-72. doi: 10.1038/ijos.2015.2.

18. Preshaw PM, Bissett SM. Periodontitis: oral complication of diabetes. Endocrinol Metab Clin North Am 2013;42:849867. doi: 10.1016/j.ecl.2013.05.012.

19. Popławska-Kita A, Siewko K, Szpak P, Król B, Telejko B, Klimiuk PA, Stokowska W, Górska M, Szelachowska M. Association between type 1 diabetes and periodontal health. Adv Med Sci 2014;59:126-131. doi: 10.1016/ j.advms.2014.01.002.

20. Xavier AC, Silva IN, Costa Fde O, Corrêa DS. [Periodontal status in children and adolescents with type 1 diabetes mellitus]. Arq Bras Endocrinol Metabol 2009;53:348-354. Portuguese.

21. Leite RS, Marlow NM, Fernandes JK, Hermayer K. Oral health and type 2 diabetes. Am J Med Sci 2013;345:271273. doi: 10.1097/MAJ.0b013e31828bdedf.

22. Lalla E, Cheng B, Lal S, Kaplan S, Softness B, Greenberg E, Goland RS, Lamster IB. Diabetes mellitus promotes periodontal destruction in children. J Clin Periodontol 2007;34:294-298. doi: 10.1111/j.1600-051X.2007.01054.x.

23. Cutler CW, Machen RL, Jotwani R, Iacopino AM. Heightened gingival inflammation and attachment loss in type 2 diabetics with hyperlipidemia. J Periodontol 1999;70:13131321. doi: 10.1902/jop.1999.70.11.1313. 